\title{
KLASIFIKASI RASA BERDASARKAN CITRA BUAH MENGGUNAKAN ALGORITMA CONVOLUTIONAL NEURAL NETWORK DENGAN TEKNIK IDENTITAS GANDA
}

\section{TASTE CLASSIFICATION BASED ON FRUIT IMAGERY USING CONVOLUTIONAL NEURAL NETWORK ALGORITHM WITH DUAL IDENTITY TECHNIQUE}

\author{
Refiani Pintanarum ${ }^{1}$, Agi Prasetiadi ${ }^{2}$, Cepi Ramdani ${ }^{3}$ \\ ${ }^{1}$ Fakultas Informatika, Teknik Informatika \\ Institut Teknologi Telkom Purwokerto \\ Email:16102100@st3telkom.ac.id
}

\begin{abstract}
Abstrak
Identitas ganda yang merupakan hal yang wajar dijumpai di dunia nyata, misal transgender salah satunya. Dalam penelitian ini, membedakan buah yang memiliki jenis rasa yang lebih dari satu, seperti buah lemon mempunyai identitas ganda yaitu asam dan asin. Untuk pengkategorisasian Deep Learning, biasanya populasi dataset training memiliki objek yang berbeda satu sama lain. Pada rasa yang terkandung dalam buah, bisa kita eksploitasi untuk melihat perilaku CNN dalam mengenali objek - objek yang memiliki identitas lebih dari satu. Adapun fase training dalam penelitian ini yaitu pada dua kategori rasa yang berbeda dengan sengaja dimasukkan beberapa citra buah yang sama ke dalam dua kategori ini. Akurasi dari pengkategorisasian ini kemudian dibandingkan dengan akurasi dari pengkategorisasian yang murni tidak terdapat objek kembar di tiap - tiap kategorinya. Dari hasil simulasi didapatkan akurasi model ketika ada identitas ganda sebesar 95\%, Adapun yang murni didapatkan sebesar $98 \%$.
\end{abstract}

Kata Kunci: Machine Learning, Deep Learning, CNN, Rasa, Buah

\begin{abstract}
Dual identity is a natural thing to find in the real world, such as transgender people. In this study, fruit with more than one taste, such as lemon, has a double identity that is acidic and salty. For Deep Learning categorization, usually, the population of training datasets has different objects from each other. In a sense contained in the fruit, we can exploit CNN behavior in recognizing objects with more than one identity. This study's training phase is in two different flavor categories deliberately inserted several images of the same fruit into these two categories. The accuracy of this categorization is then compared to the pure categorization of no
\end{abstract}


twin objects in each class. The simulation results obtained the model's accuracy when there is a double identity of $95 \%$, as for the pure obtained by $98 \%$.

\section{Keywords: Machine Learning, Deep Learning, CNN, Taste, Fruit}

\section{PENDAHULUAN}

Indonesia merupakan negara agraris. Mulai dari sisi geografis, Indonesia terletak pada daerah tropis yang memiliki curah hujan yang tinggi sehingga banyak jenis tumbuhan yang dapat hidup dan tumbuh dengan cepat[1]. Sebagian besar penduduk Indonesia mempunyai pencaharian di bidang pertanian atau becocok tanam.

Buah merupakan hasil reproduksi antara putik dan serbuk sari pada tumbuhan [2], atau juga disebut buah sejati, organ pada tumbuhan berbunga yang berasal dari perkembangan lanjutan bakal buah (ovarium). Buah merupakan pembungkus dan pelindung biji yang berkaitan dengan fungsi utama buah, yaitu sebagai pemencar biji tanaman pada tanaman berbunga. Pada umumnya buah memiliki 2 bagian utama, yaitu lapisan dinding buah, serta bagian dalam yang berisi biji. Bagian lapisan dinding buah dapat dibagi menjadi 3 lapisan, yaitu exocarp, mesocarp, dan endocarp [3].

Buah yang dapat dikonsumsi tentunya sangat bermanfaat bagi kehidupan manusia dan hewan sebagai salah satu sumber makanan. Buah salah satu komoditas holtikultura yang mempunyai peranan penting bagi pembangunan pertanian di Indonesia. Peran buah dalam tubuh sangat penting untuk metabolism tubuh karena mengandung banyak vitamin dan mineral [4].

Hortikultura

(horticulture) berasal dari bahasa Latin yaitu hortus (tanaman kebun) dan cultura/colere (budidaya), hortikultura memfokuskan pada budidaya tanaman buah (pomologi atau frutikultur), tanaman bunga (florikultura), tanaman sayuran (olerikultura), tanaman obat-obatan (biofarmaka), serta taman (lansekap)[5].

Saat ini penerapan teknologi sudah banyak dilakukan pada sektor budidaya tanaman buah seperti pemanfaatan teknologi internet of think (IoT) [6], penerapan IoT pada budidaya tanaman buah seperti pemantauan kadar $\mathrm{pH}$ [7], pengendalian suhu dan kelembaban[8]. Selain IoT pemanfaatan teknologi pada budidaya tanaman adalah machine learning [9], penerapan machine learning pada budidaya tanaman buah seperti identifikasi kematangan buah [10], tingkat kemanisan [11], jenis buah [12] dan penyakit buah [13]. Pemanfaatan teknologi IoT dan machine learning bertujuan agar budidaya tanaman buah agar lebih efisien. 
Deep Learning adalah bagian dari kecerdasan buatan dan machine learning, yang merupakan pengembangan dari neural network multiple layer untuk memberikan ketepatan tugas seperti deteksi objek[14]. Salah satu pemanfaatan dari Deep Learning yaitu bidang image processing atau pengolahan citra digital, dengan adanya image processing dimaksudkan untuk membantu manusia dalam mengenali atau mengklasifikasi objek dengan efisien yaitu cepat, tepat, dan dapat melakukan proses dengan banyak data sekaligus[15]. Salah satu metode deep learning adalah Convolutional Neural Network (CNN), CNN telah banyak dimanfaatkan pada proses efisiensi budidaya tanaman seperti kematangan buah [16], jenis buah [17] dan penyakit buah [18].

Berdasarkan latar belakang diatas, penelitian ini bertujuan untuk pemanfaatan metode $\mathrm{CNN}$ dalam mendeteksi rasa buah untuk memperkaya literatur yang berkaitan tentang korelasi bentuk buah dan rasa, serta bertujuan untuk mencari korelasi bentuk buah dan rasanya.

\section{LANDASAN TEORI}

Buah merupakan bagian tumbuhan yang berasal dari bunga, dihasilkan melalui penyerbukan antara putik dengan benang sari. Didalam buah sendiri terdapat biji yang merupakan bagian sangat penting dalam tumbuhan sebagai alat perkembangbiakan secara generatif. Hal ini terjadi karena pada biji yang ditanam nantinya akan tumbuh dan berkembang menjadi suatu individu baru dengan sifat menyerupai kedua induknya [19]. Holtikultura merupakan salah satu cabang ilmu yang membahas mengenai tanaman buah-buahan, sayur mayur, dan tanaman hias. Kata holtikultura berasal dari bahasa Latin yakni "Hortus" yang berarti tanaman kebun dan "Colere" yang memiliki arti budidaya. Sehingga dapat disimpulkan bahwa hortikultura adalah budidaya tanaman kebun. Holtikultura merupakan cabang ilmu dari agronomi. Hanya saja fokus kepada tanaman buah (pomologi atau frutikultur), tanaman sayur (olerikultura), tanaman obat-obatan (biofarmaka), dan taman (lansekap) [20].

\section{Convolutional Neural Network}

Jaringan syaraf tiruan merupakan jenis algoritma yang banyak dipakai pada konsep deep learning karena algoritma ini sangat dekat dengan konsep hierarki pada deep learning. Salah satu jenis algoritma jaringan syaraf tiruan yaitu Convolational Neural Network (CNN) merupakan pengembangan dari algoritma MultiLayer Perceptron (MLP). CNN memiliki layer convolution yang berguna untuk ekstraksi fitur data. 
CNN memiliki tiga lapisan pokok, yaitu convolution, pooling, dan fully connected layer, lebih jelasnya bisa dilihat pada gambar berikut ini.

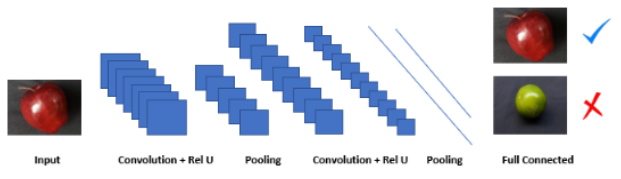

Gambar 1. Arsitektur Convolutional Neural Network

\section{Convolution Layer}

Konvolusi adalah suatu istilah matematis yang berati mengaplikasikan sebuah fungsi pada output fungsi lain secara berulang. Dalam pengolahan citra, konvolusi berati mengaplikasikan sebuah kernel (kotak kuning) pada citra disemua offset yang memungkinkan seperti yang ditunjukkan pada Tabel 2.4. Kotak hijau secara keseluruhan adalah citra yang akan dikonvolusi. Kernel bergerak dari sudut kiri atas ke kanan bawah. Sehingga hasil konvolusi dari citra tersebut dapat dilihat pada gambar disebelah kanannya.

Tabel 1. Operasi Konvolusi

\begin{tabular}{|l|l|l|}
\multicolumn{3}{c}{ Image } \\
\hline 4 & 3 & 4 \\
\hline 2 & 4 & 3 \\
\hline 2 & & \\
\hline
\end{tabular}

Convolved Feature

\section{Pooling Layer}

Pooling Layer menggunakan Feature Map, terdiri dari sebuah filter dengan ukuran dan stride tertentu yang akan bergeser pada seluruh activation map. Pooling yang digunakan adalah max dan average pooling.

\section{Fully Connected}

Fully Connected adalah layer yang biasanya digunakan dalam penerapan MLP dan bertujuan untuk melakukan transformasi pada dimensi data agar data dapat diklasifikasikan secara linear.

\section{Confusion Matrix}

Confusion Matrix merupakan sebuah tabel yang menyatakan jumlah data uji benar dan salah diklasifikasi.

\begin{tabular}{|l|l|l|l|l|}
\hline 1 & 1 & 1 & 0 & 0 \\
\hline 0 & 1 & 1 & 1 & 0 \\
\hline 0 & 0 & 1 & 1 & 1 \\
\hline 0 & 0 & 1 & 1 & 0 \\
\hline 0 & 1 & 1 & 0 & 0 \\
\hline
\end{tabular}

Metode yang biasanya digunakan untuk melakukan perhitungan akurasi pada konsep data mining atau sistem pendukung keputusan. Dalam pengukuran kinerja confusion matrix, terdapat 4 istilah sebagai representasi hasil proses klasifikasi, yaitu True Positive (TP), True Negative (TN), False Positive (FP), False Negative (FN) [21].

Tabel 2. Confusion Matrix

\begin{tabular}{|c|c|c|c|}
\hline \multicolumn{2}{|c|}{} & TRUE & FALSE \\
\cline { 3 - 4 } \multicolumn{2}{|c|}{} & 1 & 0 \\
\hline TRUE & 1 & TP & FN \\
\hline FALSE & 0 & FP & TN \\
\hline
\end{tabular}

METODE PENELITIAN 
Subjek penelitian pada tulisan ini adalah data citra buah yang diambil melalui kamera smartphone dengan resolusi gambar sebesar 4096 x 2304 pixels. Sedangkan objek penelitian berupa citra buah asli yang diambil untuk mengetahui rasa dari 27 jenis buah, yaitu rasa asam, asin, manis, pahit, dan umami, menggunakan metode Convolutional Neural Network.

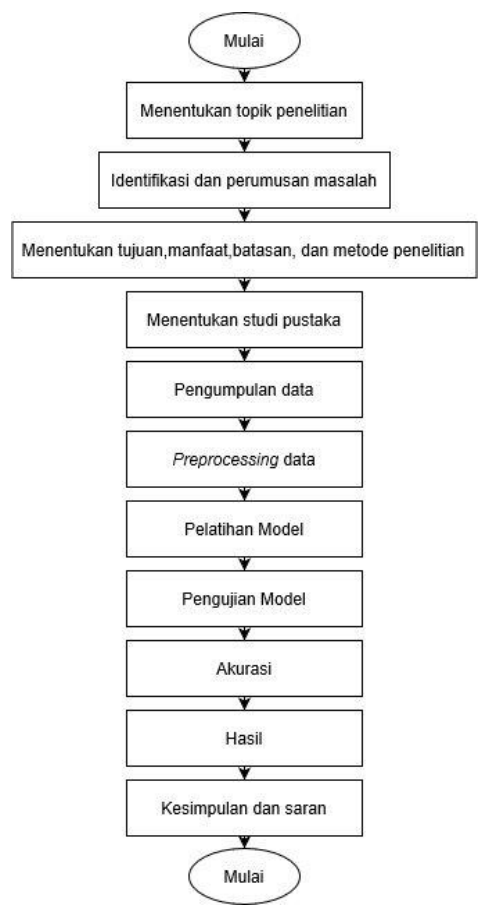

Gambar 2. Alur Diagram Penelitian

\section{PERANCANGAN SISTEM}

Berikut alur penelitian ini terdapat beberapa tahapan untuk model klasifikasi rasa buah menggunakan Convolutional Neural Network (CNN).

Gambar 3. Arsitektur Model

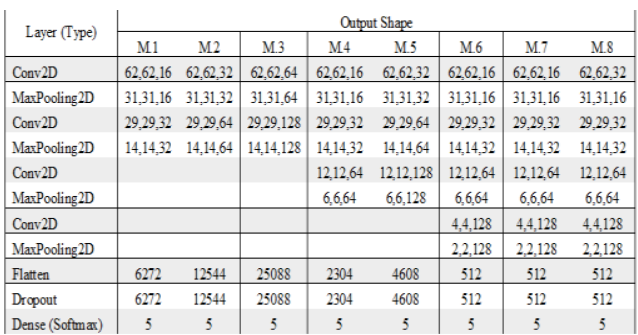

Dalam pengujian rasa diperlukan dataset yang digunakan untuk data train dan testing dan dibagi menjadi 5 class. Penulis menggunakan model dengan 8 lapisan konvolusi dan aktivasi Dense

(Softmax) sejumlah 5 class yang digunakan. Nilai epoch yang digunakanan pada ke-8 model ini yaitu sebesar 30 epoch. Dengan masing - masing model memiliki tingkatan lapisan konvolusi yang berbeda. M.1, M.2, dan M.3 menggunakan 2 layer, M.4 dan M.5 menggunakan 3 layer, M.6, M.7, dan M.8 menggunakan 4 layer.

\section{HASIL DAN PEMBAHASAN}

Peneliti melakukan klasifikasi lima kelas rasa pada buah yaitu terdapat rasa asam, asin, pahit, manis, dan umami menggunakan metode algoritma Convolutional Neural Network. Proses utama dalam pembuatan model ini diawali dengan pengumpulan data citra buah sebanyak 27000 citra, selanjutnya proses training data, untuk pengujian data testing. Citra yang terkumpul yaitu dari jenis buah kiwi, markisa, lemon, strawberry, belimbing wuluh, 
jeruk, pisang, apel, coklat, manga, karsen, melon, maja, bit, mengkudu, plum, pare, jeruk nipis, jeruk purut, markisa, nanas, alpukat, bengkoang, kenitu, naga, pir, tomat dan terong. Dari model ini dapat mengukur tingkat keberhasilan nilai akurasi, dengan nilai akurasi model ditentukan pada saat melakukan pengujian data testing. Proses training menggunakan package anaconda pada pyton dengan backend tensorflow.

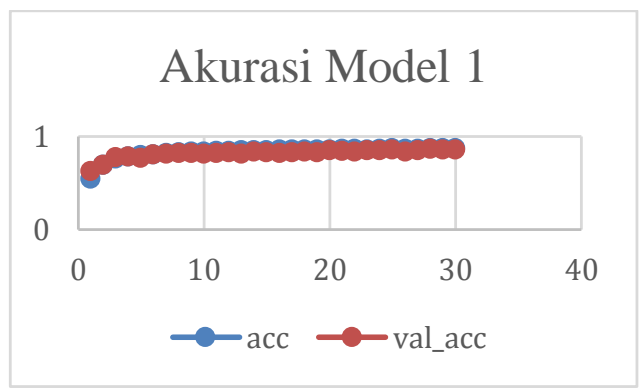

Gambar 4. Hasil Pelatihan

\section{Model 1}

Grafik hasil pelatihan model untuk menentukan akurasi. Dalam tahap pelatihan model pertama dilakukan 30step epoch dan 30 epoch. Pada model pertama, akurasi tertinggi dihasilkan sebesar $86,96 \%$ dengan membutuhkan waktu 6 jam. Sedangkan epoch ke-30 dari akurasi validasi sebesar $86,08 \%$.

\section{Akurasi Model 2}

1

0

13557911131517192123252729

$\longrightarrow$ acc $\longrightarrow$ val_acc

Gambar 5. Hasil Pelatihan

Model 2

Grafik hasil pelatihan model untuk menentukan akurasi. Dalam tahap pelatihan model pertama dilakukan 30step epoch dan 30 epoch. Pada model kedua, akurasi tertinggi dihasilkan sebesar $88,76 \%$ dengan membutuhkan waktu 7 jam. Sedangkan epoch ke-30 dari akurasi validasi sebesar $86,98 \%$.

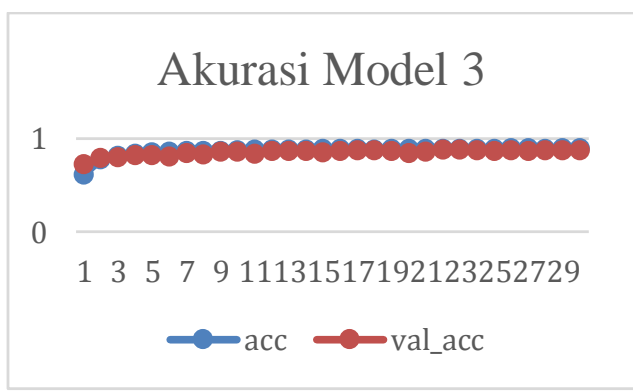

Gambar 6. Hasil Pelatihan Model 3

Grafik hasil pelatihan model untuk menentukan akurasi. Dalam tahap pelatihan model pertama dilakukan 30step epoch dan 30 epoch. Pada model kedua, akurasi tertinggi dihasilkan sebesar $89,17 \%$ dengan membutuhkan waktu 8 jam. Sedangkan epoch ke-30 dari akurasi validasi sebesar $87,77 \%$ 


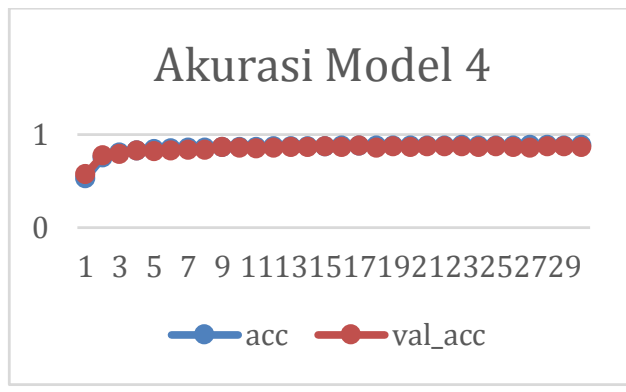

Gambar 7. Hasil Pelatihan

Model 4

Grafik hasil pelatihan model untuk menentukan akurasi. Dalam tahap pelatihan model 4 dilakukan 30step epoch dan 30 epoch, dengan akurasi tertinggi dihasilkan sebesar $88,93 \%$ dengan membutuhkan waktu 7 jam. Sedangkan epoch ke30 dari akurasi validasi sebesar $88,03 \%$.

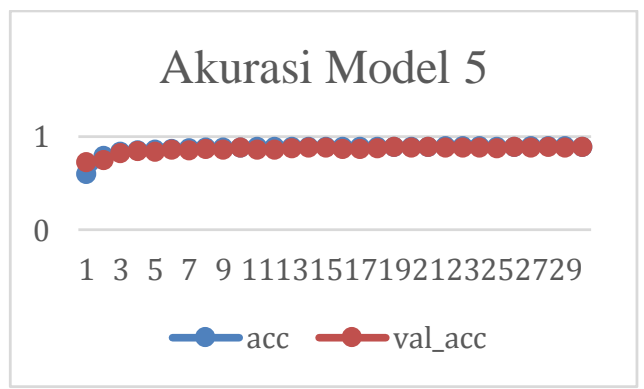

Gambar 8. Hasil Pelatihan

\section{Model 5}

Grafik hasil pelatihan model untuk menentukan akurasi. Dalam tahap pelatihan model 5 dilakukan 30step epoch dan 30 epoch, dengan akurasi tertinggi dihasilkan sebesar $89,45 \%$ dengan membutuhkan waktu 7 jam. Sedangkan epoch ke30 dari akurasi validasi sebesar $88,47 \%$.

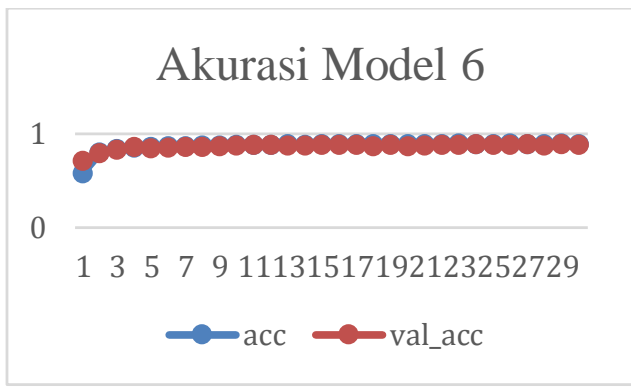

Gambar 9. Hasil Pelatihan

Model 6

Grafik hasil pelatihan model untuk menentukan akurasi. Dalam tahap pelatihan model 6 dilakukan 30 step epoch dan 30 epoch, dengan akurasi tertinggi dihasilkan sebesar $89,24 \%$ dengan membutuhkan waktu 7 jam. Sedangkan epoch ke30 dari akurasi validasi sebesar $88,75 \%$.

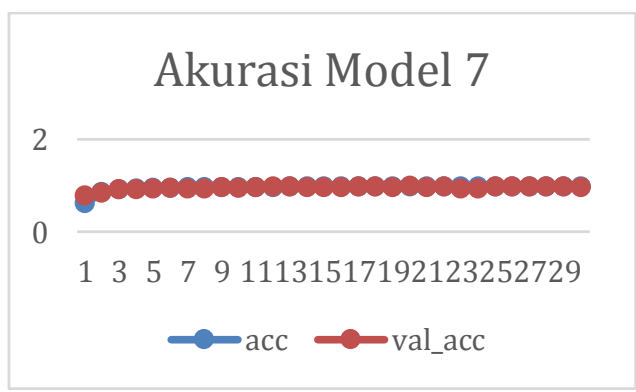

Gambar 10. Hasil Pelatihan Model 7

Grafik hasil pelatihan model untuk menentukan akurasi. Dalam tahap pelatihan model 7A dilakukan 30step epoch dan 30 epoch, dengan akurasi tertinggi dihasilkan sebesar $98,86 \%$ dengan membutuhkan waktu 6 jam. Sedangkan epoch ke30 dari akurasi validasi sebesar $98,59 \%$. 


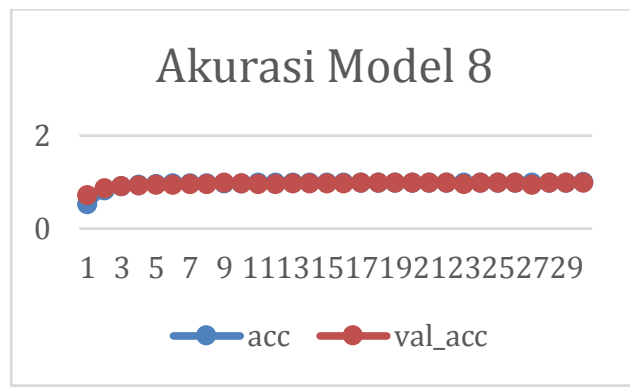

Gambar 11. Hasil Pelatihan

Model 8

Grafik hasil pelatihan model untuk menentukan akurasi. Dalam tahap pelatihan model 7B dilakukan 30step epoch dan 30 epoch, dengan akurasi tertinggi dihasilkan sebesar 99,14\% dengan membutuhkan waktu 6 jam. Sedangkan epoch ke30 dari akurasi validasi sebesar $99,00 \%$.

\begin{tabular}{|c|c|c|c|c|ccc|c|c|}
\multirow{2}{*}{ Jenis } & \multirow{2}{*}{ Kode Uji } & \multicolumn{8}{|c|}{ Model } \\
\cline { 3 - 10 } & & M.1 & M.2 & M.3 & M.4 & M.5 & M.6 & M.7 & M.8 \\
\hline Asam & 0 & 680 & 849 & 809 & 921 & 806 & 782 & 594 & 593 \\
Asin & 1 & 1069 & 895 & 904 & 852 & 953 & 979 & 966 & 599 \\
Manis & 2 & 1112 & 1110 & 1160 & 1166 & 1160 & 1192 & 1190 & 1190 \\
\hline Pahit & 3 & 1161 & 1157 & 1161 & 1090 & 1197 & 1158 & 1161 & 1152 \\
\hline Umami & 4 & 1148 & 1192 & 1192 & 1183 & 1187 & 1196 & 1017 & 1195 \\
\hline Total Probabilitas Akurasi & $86 \%$ & $86 \%$ & $87 \%$ & $86 \%$ & $88 \%$ & $88 \%$ & $95 \%$ & $98 \%$
\end{tabular}

Gambar 12. Hasil Total Probabilitas

\section{Akurasi}

Pada pengujian dataset dengan kode uji asam 0 , asin 1 , manis 2 , pahit 3, dan umami 4. Dari model 1 hingga model 8 diperoleh hasil total akurasi tertinggi yang dimiliki oleh model 8 yaitu sebesar $98 \%$. Setelah probabilitas diketahui, maka model 8 dapat digunakan dalam mengidentifikasi citra RGB dari jenis buah ganda dengan akurat.

Model terbaik adalah model ke8 dengan akurasi total $98 \%$. Berikut adalah confusion matrixnya.

\begin{tabular}{|c|c|c|c|c|c|c|c|}
\hline label & asam & asin & manis & pahit & umami & total & Akurasi \\
\hline asam & 593 & 6 & 0 & 0 & 1 & 600 & 0,988333 \\
\hline asin & 0 & 599 & 0 & 0 & 1 & 600 & 0,998333 \\
\hline manis & 5 & 3 & 1190 & 2 & 0 & 1200 & 0,991667 \\
\hline pahit & 0 & 5 & 35 & 1152 & 8 & 1200 & 0,96 \\
\hline umami & 0 & 0 & 3 & 2 & 1195 & 1200 & 0,995833 \\
\hline \multicolumn{8}{|c|}{ Rata - Rata Akhir } \\
\hline
\end{tabular}

Gambar 13. Confusion Matrix

\section{KESIMPULAN}

Dalam menggunakan metode CNN memerlukan 4 Convolution Layer, aktivasi ReLU, Dropout, dan Dense (Softmax), yang diterapkan dalam membangun arsitektur model CNN untuk mengidentifikasi suatu citra input. Model klasifikasi jenis buah menggunakan dataset yang berisikan hasil augmentasi data citra asli pada 27 jenis buah, yang masingmasing jenis di klasifikasi berdasarkan rasa asam, asin, manis, pahit, dan umami. Dalam menentukan akurasi terbaik dibutuhkan nilai sebanyak 30 epoch. Modeling pada class yang memiliki identitas ganda, akan mengakibatkan penurunan akurasi pada salah satu class, bahkan tidak terdeteksi bahwa buah tersebut buah yang akan identifikasi atau bukan. Jika modeling sedang berjalan class yang teridentifikasi hanya salah satu class asam atau asin, dari modeling yang dibuat penulis, class dengan akurasi lebih baik berdominan pada class asin model 6 dengan akurasi $81 \%$, menggunakan 30 epoch. Maka penulis menambahkan 2 model yaitu model 7 dan model 8 untuk 
mengoptimalkan akurasi dan identifikasi rasa pada jenis buah ganda tersebut dan mendapati akurasi model 7 sebesar $99 \%$ class asam dan class asin $80 \%$, model 8 sebesar $98 \%$ class asam, sedangkan class asin 99\% dengan nilai epoch sebanyak 30epoch.

\section{DAFTAR PUSTAKA}

[1] P. A. Julianto, "Negara Agraris," 2017.

[2] L. H. Nugroho and I. Sumardi, Biologi Dasar. 2004.

[3] Rimba, "Pengertian Buah, Jenis, Bagian dan Fungsi," 2019. .

[4] Sinta, "Pengertian Buah-buahan Lokal," vol. 11, no. 2, pp. 10-14, 2011.

[5] M. Pertanian, "Pengertian Hortikultura, Macam, Ciri, Manfaat, dan Contohnya," 2018. .

[6] M. I. Abriyantoro, "Rancang Bangun Prototipe Rumah Kaca Pintar Berbasis IoT (Internet of Things) Untuk Budidaya Tanaman Tomat," 2020. http://repository.its.ac.id/id/epri nt/77220.

[7] A. Qalit and A. Rahman, "Rancang Bangun Prototipe Pemantauan Kadar Ph Dan Kontrol Suhu Serta Pemberian Pakan Otomatis Pada Budidaya Ikan Lele Sangkuriang Berbasis Iot," J. Karya Ilm. Tek. Elektro, vol. 2, no. 3, pp. 8-15, 2017.
[8] S. A. Helmy Fitriawan, Kholid Ali Dwi Cahyo, Sri Purwiyanti, "Pengendalian Suhu dan Kelembaban Pda Budidaya Jamur Tiram Berbasis IoT, " vol. 21, no. 1, pp. 1-9, 2020.

[9] H. Suroyo, "Penerapan Machine Learning dengan Aplikasi Orange Data Mining Untuk Menentukan Jenis Buah Mangga," Semin. Nas. Teknol. Komput. Sains, vol. 1, no. 1, pp. 343-347, 2019, [Online]. Available:

https://prosiding.seminarid.com/index.php/sainteks/articl e/view/177.

[10]H. M. Helmy Noor, Moch, "Image Cluster Berdasarkan Warna Untuk Identifikasi Kematangan Buah Tomat dengan Metode Valley Tracing," vol. 2009, no. semnasIF, pp. 15-24, 2009.

[11]Z. M. S. Muhammad Ichwan, Irma Amelia Dewi, "Klasifikasi Support Vector Machine (SVM) Untuk Menentukan Tingkat Kemanisan Mangga Berdasarkan Fitur Warna," MIND J., vol. 3, no. 2, pp. 1623, 2019, doi: 10.26760/mindjournal.v3i2.1623.

[12]A. Saputra, "Klasifikasi Pengenalan Buah Menggunakan Algoritma Naive Baiyes," J. Resist. (Rekayasa 
Sist. Komputer), vol. 2, no. 2, pp. 83-88, 2019, doi: 10.31598/jurnalresistor.v2i2.43 4.

[13]F. H. Nashrullah, "Deteksi Penyakit Tanaman Tomat Melalui Tekstur Daun dengan Metode Gabor Filter," 2020.

[14]S. Sena, "Pengenalan Deep Learning Convolutional Neural Network," 2017.

[15]F. F. Maulana and N. Rochmawati, "Klasifikasi Citra Buah Menggunakan Convolutional Neural Network," J. Informatics Comput. Sci., vol. 01, pp. 104108, 2019.

[16]F. Kirom, "Klasifikasi Kematangan Buah Kelapa Sawit Per Tandan Untuk Keperluan Penjaminan Kualitas Crude Palm Oil (CPO) Menggunakan Metode Convolutional Neural Network (CNN)," 2018.

[17]W. S. Eka Putra, "Klasifikasi Citra Menggunakan Convolutional Neural Network (CNN) pada Caltech 101," J. Tek. ITS, vol. 5, no. 1, 2016, doi: 10.12962/j23373539.v5i1.1569 6.

[18]M. M. F. Alim, "Identifikasi Penyakit Tanaman Tomat Menggunakan Algoritma Convolutional Neural Network dan Pendekatan Transfer Learning," 2020.
[19]M. Pertanian, "Pengertian Buah, Manfaat, Tipe Penggolongan, Dan Contohnya." 2019.

[20]Ika Lestari, "Pengertian Hortikultura, Manfaat dan Jenis," 2020. https://pendidikan.co.id/pengert ian-derivatif-transaksi-alasanpelaku-manfaat-dan-jenis/.

[21]A. M. H. Y. Bambang Nurcahyo Prastowo, Nur Achmad Sulistyo Putro, Oktaf Agni Dhewa, "Pengenalan Personal Menggunakan Citra Tampak Atas pada Lingkungan Cashierless Store," J. Buana Inform., vol. 10, no. 1, p. 19, 2019 , doi: 10.24002/jbi.v10i1.1779. 